\title{
Association between clinicopathological features and prognosis significance of PD-L1 expression in small cell lung cancer patients: a systemic review and meta-analysis
}

\author{
Zongtao $\mathrm{Hu}^{1}$, Lin $\mathrm{Lu}^{2}$, Zhenle Fei ${ }^{2}$, Donglai $\mathrm{Lv}^{1,2}$ \\ ${ }^{1}$ Hefei Cancer Hospital, Chinese Academy of Sciences, Hefei, China; ${ }^{2}$ Department of Clinical Oncology, 901 Hospital of Joint Logistics Support \\ Force of People Liberation Army, Hefei, China \\ Contributions: (I) Conception and design: Z Hu, D Lv; (II) Administrative support: Z Hu, D Lv; (III) Provision of study materials: All authors; (IV) \\ Collection and assembly of data: All authors; (V) Data analysis and interpretation: All authors; (VI) Manuscript writing: All authors; (VII) Final \\ approval of manuscript: All authors. \\ Correspondence to: Donglai Lv. Hefei Cancer Hospital, Chinese Academy of Sciences, Hefei, 230031, China. Email: lvxunhuan@163.com.
}

\begin{abstract}
Background: Programmed death ligand-1 (PD-L1) has been identified as an established biomarker for predicting response to immunotherapy in a variety types of cancer. However, the clinicopathological and prognostic significance of this protein in small cell lung cancer (SCLC) patients remains controversial.

Methods: Eligible studies extracted from the databases of PubMed, MEDLINE, Embase, and CNKI databases were evaluated. Statistical analysis was performed using STATA 11.2 software.

Results: A total of 483 PD-L1+ cases and 570 controls from 11 publications were extracted. Either overall analysis or subcategory analysis showed that no significant association between higher PD-L1 expression and gender ( $\mathrm{n}=8$, OR 1.08, 95\% CI: 0.73-1.61, $\left.\mathrm{P}=0.704, \mathrm{I}^{2}=0.0 \%\right)$, tumor stage $(\mathrm{n}=5$, OR $0.71,95 \%$ CI: $\left.0.20-2.56, \mathrm{P}=0.599, \mathrm{I}^{2}=86.5 \%\right)$, smoking status ( $\mathrm{n}=4$, OR $\left.0.85,95 \% \mathrm{CI}: 0.41-1.73, \mathrm{P}=0.646, \mathrm{I}^{2}=0.0 \%\right)$, and the level of serum lactate dehydrogenase $(\mathrm{LDH})\left(\mathrm{n}=4\right.$, OR $0.76,95 \% \mathrm{CI}: 0.48-1.20, \mathrm{P}=0.241, \mathrm{I}^{2}=21.6 \%$ ). PD-L1 expression had no positive correlation with overall survival (OS) ( $\mathrm{n}=11$, HR 0.97, 95\% CI: 0.61-1.56, $\mathrm{P}=0.904, \mathrm{I}^{2}=83.2 \%$ ) in overall analysis. However, the stratified analysis showed that increased expression of PD-L1 predicted a significantly better OS in monoclonal antibody (mAb) subgroup and Food and Drug Administration (FDA) approved antibody clone specification (22C3/28-8/SP142/SP263) subgroup without significant heterogeneity.
\end{abstract}

Conclusions: PD-L1 is not an important predictor of most clinicopathological features of SCLC patients, but it can predict an improved survival when using mAb or FDA approved clone specifications in IHC assays.

Keywords: Small cell lung cancer (SCLC); programmed death ligand-1 (PD-L1); clinicopathology; prognosis

Submitted Mar 15, 2020. Accepted for publication Jul 27, 2020.

doi: $10.21037 /$ tcr-20-1512a

View this article at: http://dx.doi.org/10.21037/tcr-20-1512a

\section{Introduction}

Small cell lung cancer (SCLC), accounts for $15-20 \%$ of all lung cancer cases, is one of the most aggressive cancers due to its metastasis and recurrence behaviors (1). Traditionally, a combination of radiotherapy and chemotherapy was the first-line regimen. However, patients with SCLC still have a poor prognosis after effective treatment, with a 5 -year survival rate of less than $5 \%$. For patients who did not receive any active treatments, the median survival was only 2-4 months (2).

Programmed death ligand-1 (PD-L1), also known as CD274 and B7-H1, is a transmembrane protein commonly expressed on the surface of antigen presenting cells and tumor cells. Recent studies have shown that blocking the immune checkpoints programmed death-1 (PD-1) and PD-L1 with monoclonal antibodies is a potential new 
therapeutic strategy in SCLC (3). The PD-L1 inhibitor atezolizumab, combined with carboplatin and etoposide, had proved efficacy in the first-line treatment of extensivestage SCLC (4). Moreover, PD-L1 expression might be associated with the efficacy of chemotherapy treatment in SCLC (5).

Despite numerous independent studies, the relationship between PD-L1 expression and the clinicopathologic characteristics and prognostic parameters in SCLC remained controversial. Some studies suggested that a higher PD-L1 expression was related to an earlier stage and predicted a better prognosis. For example, in a series of 102 SCLC patients, the PD-L1 expression detected by immunostaining was positively correlated with the LD stage and predicted a favorable outcome (6). The similar results reported that a combined detection of PD-L1/ c-MET expression might be a useful panel in the prediction of SCLC patients (7). By contrast, some other researchers demonstrated that the presence of high PD-L1-expressing tumor cells was associated with advanced stage and poor survival in 186 cases of SCLC (8).

In this study, we performed a meta-analysis to systematically assess the relationship between PD-L1 expression and clinicopathology and prognosis in SCLC patients.

We present the following article in accordance with the PRISMA reporting checklist (available at http://dx.doi. org/10.21037/tcr-20-1512a).

\section{Methods}

\section{Search strategy}

Case-control or cohort studies were mainly identified by conducting a systematic search in PubMed, MEDLINE, Embase, and CNKI databases using the following terms: "PD-L1", "B7-H1","CD274", "small cell lung cancer", "prognosis" and "survival". Reference lists from relevant articles were also examined to find additional publications. All studies were published prior to September 23, 2019. In the initial retrieved literatures, we read the titles or abstracts and screened for prognosis and clinicopathology related research. Studies were included when the following criteria were met: (I) published in English or Chinese with the full text available, (II) the use of a case-control design or a cohort design, (III) the main outcome of interest focused on the clinicopathological features, and survival, and (IV) the availability of data to allow the estimation of the hazard ratio (HR) for survival with a $95 \%$ confidence intervals (CI). Accordingly, the exclusion criteria were as follows: (I) reviews, abstracts and repeated studies; (II) the use of duplicate data. No ethnicity or regional restrictions were applied. If an eligible study was retrieved in duplication, only the latest one was included. The review process was performed by two independent reviewers.

\section{Data extraction}

The following information was extracted from these papers based the criteria listed above: first author, patients' country, publication year, research technique used, number of cases and controls, tumor stage, antibody information (including general information, type, host animal, and clone specification for monoclonal antibodies), cutoff value for PD-L1 positive, mean age, anti-cancer therapy, and prognostic outcomes (OS). Any discrepancies were resolved through discussion amongst the authors.

\section{Statistical analysis}

Statistical calculations were all performed by using STATA 11.2 statistical software (STATA Corp., College Station, TX, USA). Pooled odds ratio (OR) or HR and their corresponding $95 \% \mathrm{CI}$ of OS were counted. A HR less than one was defined as a better prognosis in SCLC patients with PD-L1 positive expression, whereas a HR more than one indicated a worse prognosis. Other clinicopathological factors were sorted into several subgroups: gender, tumor stage [limited disease (LD) and extensive disease (ED)], smoking status, and the lever of serum lactate dehydrogenase (LDH). In addition, stratified analyses were performed to investigate the potential causes of heterogeneity according to mean age of patients, tumor stage, cutoff value of PD-L1 expression, antibody clone and antibody type used. Fixed and random effects models were used to calculate a pooled OR and HR. The statistical significance of the pooled OR and $\mathrm{HR}$ was evaluated with the $\mathrm{Z}$ test and $\mathrm{P}$ values. All $\mathrm{P}$ values were two-sided and a $\mathrm{P}<0.05$ was considered to be statistically significant. Heterogeneity across studies was evaluated by applying a Cochrane's Q test. In this approach, the $\mathrm{Q}$ value is defined as identical to the effect size of the $\mathrm{I}^{2}$ value. A random effects model was used when the $\mathrm{I}^{2}$ value for heterogeneity test was $>50 \%$; otherwise, a fixed effects model was used. Begg's rank correlation method (9) were used to assess publication bias $(\mathrm{P}<0.05$ was considered to be statistically significant). Sensitivity analysis was performed 


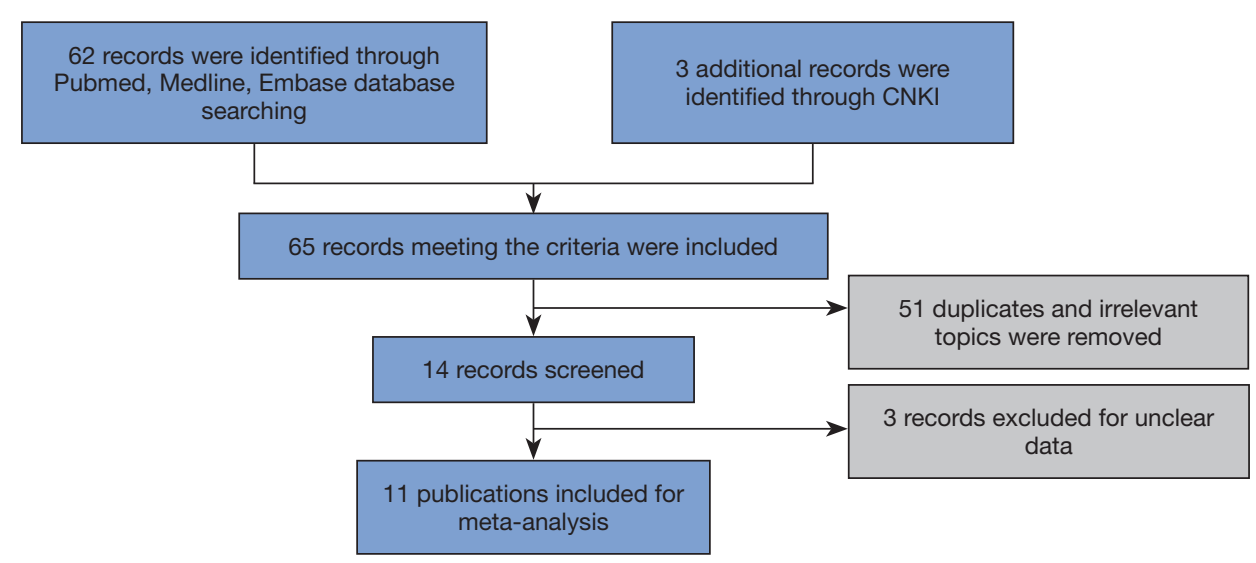

Figure 1 Flow chart of eligible study identification. 11 articles were included eventually according to inclusion criteria.

to examine the stability of the pooled results.

\section{Results}

\section{Study characteristics}

A total of 11 publications $(6-9,10-17)$ range from 2015 to 2019 were identified to meet the criteria for this analysis. The flow chart for the identification of eligible studies was shown in Figure 1. The total number of SCLC patients was 1,303 , including 483 cases (PD-L1 positive) and 570 controls (PD-L1 negative). Immunohistochemistry (IHC) was a primary method used to evaluate PD-L1 expression in SCLC specimens. The main characteristics of the 11 eligible studies were summarized in Table 1 .

The mean age of patients ranged from 54 to 70 years old. Eight studies reported the data of gender distribution. In terms of the extent of disease, two trials focused on the LD-SCLC, one trial focused on the ED-SCLC, while eight trials included both patients with LD-SCLC and EDSCLC. The patients in all studies received chemotherapy or chemoradiotherapy, and a portion of patients in seven studies underwent surgical resection. For uniformed data assessment, in the analysis of PD-L1 expression cutoff value, we integrated $\geq 5 \%$ expression group $v s . \geq 1 \%$ expression group. In order to clarify the possible effects of antibodies subtype, all anti-PD-L1 antibodies were specified precisely according to different type [monoclonal antibody (mAb) vs. polyclonal antibody (pAb)], and clone specification for mAb. There were several PD-L1 IHC assays registered in the Food and Drug Administration (FDA), using four different PD-L1 antibody clones (22C3, 28-8, SP263, SP142) (18).
Therefore, the four kinds of antibodies were considered as one group, the rest antibodies without FDA approval were considered as other group.

\section{Results}

\section{Correlation of PD-L1 expression with clinicopathological parameters}

To determine the value of PD-L1 in pathological diagnosis, we investigated the association of PD-L1 expression with some clinicopathological data. As shown in Figure 2 , the overall analysis showed no significant association between higher PD-L1 expression and gender $(n=8, O R$ $1.08,95 \%$ CI: $0.73-1.61, \mathrm{P}=0.704, \mathrm{I}^{2}=0.0 \%$ ), tumor stage $\left(\mathrm{n}=5\right.$, OR $0.71,95 \%$ CI: $\left.0.20-2.56, \mathrm{P}=0.599, \mathrm{I}^{2}=86.5 \%\right)$, smoking status ( $\mathrm{n}=4$, OR $0.85,95 \%$ CI: $0.41-1.73, \mathrm{P}=0.646$, $\left.\mathrm{I}^{2}=0.0 \%\right)$, and the level of serum LDH $(\mathrm{n}=4$, OR $0.76,95 \%$ CI: $0.48-1.20, \mathrm{P}=0.241, \mathrm{I}^{2}=21.6 \%$ ).

Subsequently, we performed a subcategory analysis according to different mean ages of patients ( $>65$ and $\leq 65$ subgroups), different cutoff values of PD-L1 expression ( $\geq 5 \%$ and $\geq 1 \%$ subgroups), different clinical stages of the patients (LD+ED and LD subgroups), different clones of antibodies (22C3/28-8/SP142 and other subgroups), and different antibody types (mAb and pAb subgroups). Later tumor stage in the PD-L1 positive group could be found in the subgroup studies with antibody used type pAb. As a result, all of these four clinicopathological parameters were not correlated with PD-L1 expression in stratification analyses, which were consistent with the results derived from overall analyses. The results are shown in Table 2. 
Table 1 Main characteristics of the eligible studies

\begin{tabular}{|c|c|c|c|c|c|c|c|c|c|c|c|}
\hline Author & Country & Year & Tech. & $\begin{array}{c}\text { Cases } \\
(\mathrm{PD}-\mathrm{L} 1+)\end{array}$ & $\begin{array}{l}\text { Controls } \\
\text { (PD-L1-) }\end{array}$ & stage & $\begin{array}{c}\text { Mean age } \\
\text { (years) }\end{array}$ & $\begin{array}{l}\text { Cutoff of } \\
\text { positive }\end{array}$ & $\begin{array}{l}\text { Clone of } \\
\text { antibody }\end{array}$ & Therapy & $\mathrm{HR}(95 \% \mathrm{Cl})$ \\
\hline Ishii (6) & Japan & 2015 & $\mathrm{IHC}$ & 73 & 29 & $\mathrm{LD}+\mathrm{ED}$ & 70 & $\geq 5 \%$ & 28-8 (Abcam) & surg.+ C/CR. & $0.44(0.24-0.80)$ \\
\hline Miao (8) & China & 2017 & $\mathrm{IHC}$ & 43 & 40 & LD+ED & 59 & $\geq 5 \%$ & SP66 (Springbio) & surg.+ C/CR. & $0.94(0.57-1.56)$ \\
\hline Yu (11) & America & 2017 & $\mathrm{IHC}$ & 13 & 74 & ED & NA & $\geq 1 \%$ & 28-8 (Dako) & $\mathrm{C} / \mathrm{CR}$. & $0.43(0.179-1.07)$ \\
\hline Kim (12) & Korea & 2018 & $\mathrm{IHC}$ & 17 & 103 & $\mathrm{LD}+\mathrm{ED}$ & 66 & $\geq 1 \%$ & 130021 (R\&D) & surg.+ C/CR. & $1.15(0.76-1.73)$ \\
\hline Liu (13) & China & 2018 & $\mathrm{IHC}$ & 52 & 28 & LD & 54 & $\geq 5 \%$ & SP142 (Springbio) & surg.+ C/CR. & $0.48(0.28-0.85)$ \\
\hline $\operatorname{Jin}(14)$ & China & 2018 & $\mathrm{IHC}$ & 48 & 50 & $\mathrm{LD}+\mathrm{ED}$ & & $\geq 5 \%$ & NA (Proteintech) & $\mathrm{C} / \mathrm{CR}$. & $1.86(1.24-2.76)$ \\
\hline Qiu (17) & China & 2019 & $\mathrm{IHC}$ & 39 & 25 & $\mathrm{LD}+\mathrm{ED}$ & 59 & $\geq 5 \%$ & SP142 (Zsbio) & $\mathrm{C} / \mathrm{CR}$. & $0.41(0.13-1.26)$ \\
\hline
\end{tabular}

LD and ED stage was defined as limited disease and extensive disease stage; TMA was defined as tissue microarrays; C/CR. was defined as chemotherapy or chemoradiotherapy; NA was defined as no accessed.

A

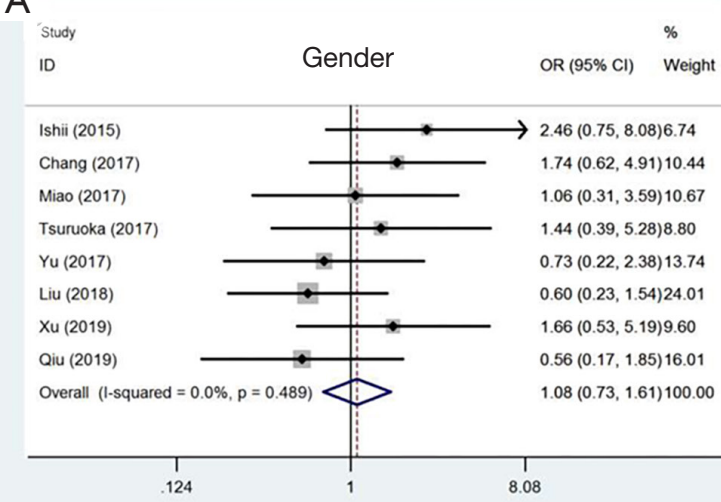

C

Study

ID

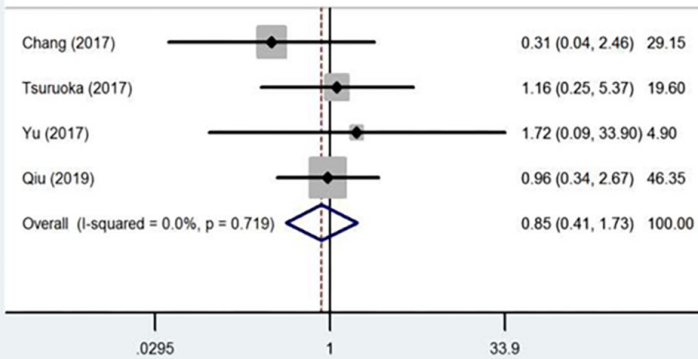

B

Stud
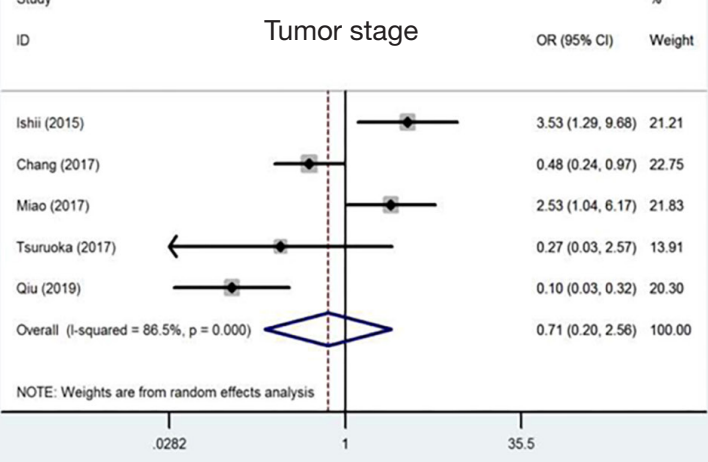

D

Study

10

Serum LDH

OR $(95 \% \mathrm{Cl}) \quad$ Weight

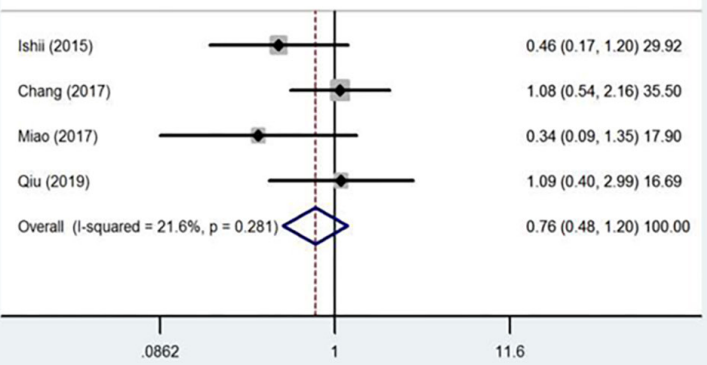

Figure 2 Meta-analysis of the association between PD-L1 expression and clinicopathological parameters: (A) gender; (B) tumor stage; (C) smoking status; (D) the lever of serum LDH. 


\section{Impact of PD-L1 expression on survival for SCLC patients}

To further evaluate the relationship between PD-L1 and prognosis in SCLC patients, survival analysis of OS was conducted. As showed in Figure 3, a random effect model revealed that high PD-L1 expression was not significantly associated with OS ( $\mathrm{n}=11$, HR $0.97,95 \%$ CI: $0.61-1.56$, $\left.\mathrm{P}=0.904, \mathrm{I}^{2}=83.2 \%\right)$. Further subgroup analyses stratified by the mean age of the patients, cutoff values of PDL1 expression, tumor stage, different antibody type and clone specification were conducted. The results showed that no significant association between OS and PD-L1 expression was observed in different mean age subgroups, PD-L1 cutoff values subgroups and tumor stage subgroups. Interestingly, the stratified analysis of OS and PD-L1 expression in different antibody clone specification and type subgroups showed that increased expression of PD-L1 predicted a significantly better OS in 22C3/28-8/SP142/ SP263 subgroup and mAb subgroup, while a significantly worse $\mathrm{OS}$ in other clone specification subgroup and $\mathrm{pAb}$ subgroup.

It should be noted that the result of the overall analysis had obvious heterogeneity $\left(\mathrm{I}^{2}=82.4 \%\right)$. In the mAb subgroup, $\mathrm{I}^{2}$ decreased to $46.3 \%$, while in the $\mathrm{pAb}$ subgroup, $\mathrm{I}^{2}$ was still as high as $73.7 \%$. $\mathrm{I}^{2}$ was reduced to $0 \%$ when $\mathrm{mAb}$ subgroup was further restricted to FDA approved 22C3/28-8/SP142/SP263 clone. The results were shown in Table 2 and Figure 3.

\section{Publication bias}

Begg's funnel plot and Egger's test were used to evaluate the publication bias of all the relevant literatures. The statistical results did not show evidence of publication bias: gender: Begg's test, $\mathrm{P}=0.902$, Egger's test, $\mathrm{P}=0.495$; tumor stage: Begg's test, $\mathrm{P}=1.000$, Egger's test, $\mathrm{P}=0.773$; smoking status: Begg's test, $\mathrm{P}=0.734$, Egger's test, $\mathrm{P}=0.859$; and the lever of serum LDH: Begg's test, $\mathrm{P}=0.308$, Egger's test, $\mathrm{P}=0.260$. Similar results were found for OS: Begg's test, $\mathrm{P}=0.436$, Egger's test, $\mathrm{P}=0.494$. The funnel plot used to investigate the relationship between PD-L1 expression and OS was shown in Figure 4. The shape of the funnel plot did not show obvious evidence of asymmetry.

\section{Sensitivity analysis}

Sensitivity analysis of our meta-analysis was performed through the sequential omission of individual studies according to the method of Duval et al. (19). The corresponding pooled OR was not altered significantly for any study factor after sequentially excluding each study, demonstrating that our data were stable, reliable in this analysis. The detailed results were shown in Figure 5.

\section{Discussion}

PD-L1 is the ligand of PD-1, which plays an important role in inhibiting $\mathrm{T}$ lymphocytes activation and inducing immune tolerance. The blockade of this ligand leads to successful immunotherapies by enhancing $T$ cell immune responses against tumor cells. In most clinical trials, PDL1 protein expression on tumor cells detected by IHC was an important predictive biomarker (20-22). Therefore, many institutions had investigated the relationship between the expression of PD-L1 and the clinicopathological features and prognosis of SCLC patients. However, the clinical significance of PD-L1 in diagnosis and treatment was still controversial in SCLC. For instance, the research by Kim et al. suggested that PD-L1 was not a prognostic factor in SCLC patients (12). On the contrary, several studies reported that PD-L1 was a poor survival prognostic marker (16). Based on these controversial studies, our aim was to evaluate the precise impacts of PD-L1 on clinicopathological features and prognosis of SCLC patients.

In this study, we summarized the outcomes of 1303 SCLC patients from 11 relevant publications related to PD-L1, prognosis, and pathology in SCLC specimen. Our results derived from this meta-analysis of existing studies indicated that PD-L1 could not be used as a better or worse OS prognostic indicator and the increased expression of PD-L1 had no positive association with most clinicopathological features in SCLC patients. Specifically, no patients in this study had received immunotherapy with PD-1/PD-L1 antibody, thus the result could accurately reflect the association between native $\mathrm{PD}-\mathrm{L} 1$ expression status and overall survival. Similar results had been found in the study of melanoma, which revealed no relevant PDL1 expression on primary or metastatic tumor stages and no significant correlations with prognosis were found regarding this immunological factor (23). Moreover, it was also found that the results had a significant heterogeneity, which was mainly caused by the differences of IHC antibodies. Previous study suggested that the differences among the samples obtained, the antibodies used, and the defined cut off values might contribute to the inconsistent 


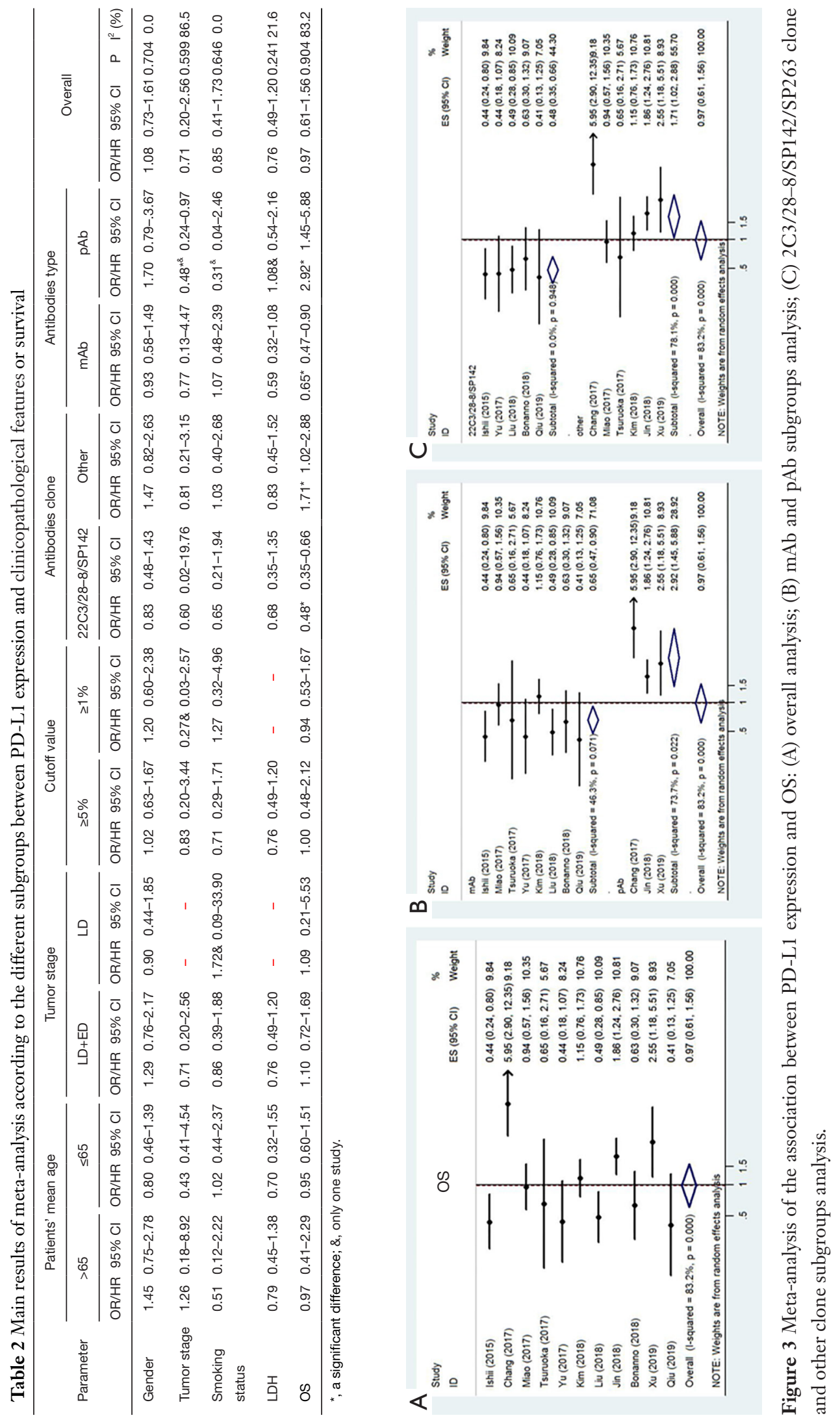




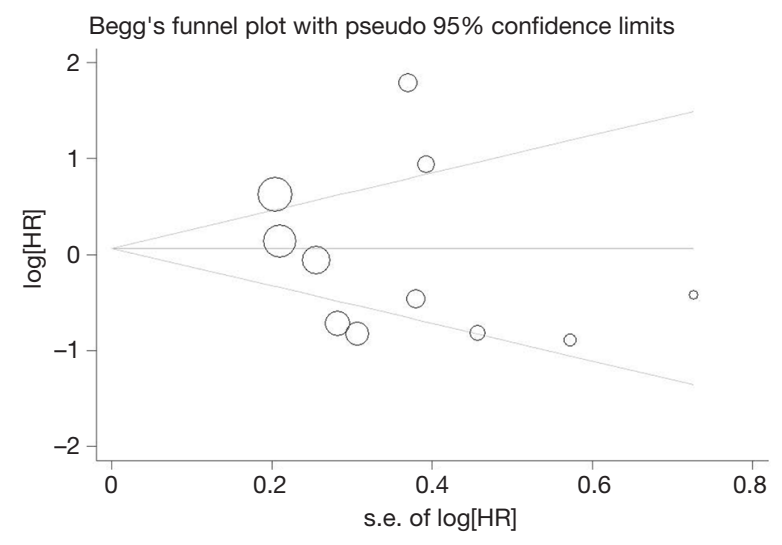

Figure 4 Begg's funnel plot for publication bias test. Each point represents a separate study for the indicated association (OS).

results $(24,25)$. The results of our meta-analysis showed monoclonal antibodies were more effective than polyclonal antibodies in reducing the detection heterogeneity, while the four FDA approved clone specifications had the best consistency.

The relationship between PD-L1 expression and tumor progression remained unclear. Some earlier studies reported that expression of PD-L1 protein was associated with poor prognosis in patients with NSCLC, esophageal carcinoma, gastric carcinoma, hepatocellular carcinoma, pancreatic carcinoma, and renal cell carcinoma (26-32). However, it also found that expression of PD-L1 was associated with better prognosis in patients with several solid tumors including NSCLC, colorectal cancer, and breast cancer (33-35). These contradictory conclusions might be due to several reasons. Firstly, previous researches had not standardized the use of antibodies, and various antibodies in different studies would seriously affect the quality and homogeneity of results. In our study, the result of prognosis was completely opposite between mAb and pAb subgroups, and this contradiction was partly due to the strong heterogeneity by using polyclonal antibody or non-FDA approved clone specifications. When this heterogeneity was minimized by stratified analysis, the higher PD-L1 expression could predict an improved survival prognosis (HR=0.48, 95\% CI: 0.35-0.66) in SCLC. Interestingly, our finding was consistent with the latest published literature, which represented the largest cohort of cases in the association study between PD-L1 expression and survival in NSCLC patients so far. ALL IHC staining was carried out using the FDA approved Dako 28-8 assay

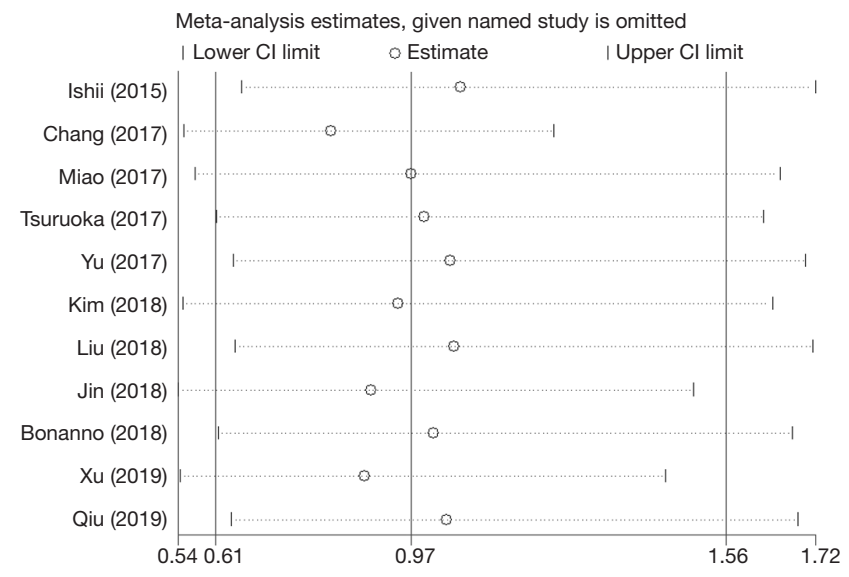

Figure 5 Sensitivity analyses of the PD-L1 expression with OS for the meta-analysis assessing. Omission of any study did not affect the whole estimate results significantly in all outcomes.

in that study (36). Secondly, previous studies had shown that PD-L1 expression was driven by various oncogenic signaling pathways (37). Finally, the effective chemotherapy, which was an important factor for better prognosis in SCLC, might weaken anti-tumor immunity by regulating the expression of PD-L1.

Some limitations of this meta-analysis also should be noted. First of all, all studies included in our meta-analyses were retrospective. Larger multicenter prospective studies based on homogeneous populations were necessary in the future. Moreover, publication bias was inevitable. The assay used SP142 antibody detected both tumor cells and immune cells into a combined score. However, the assay used 22C3, 28-8 and SP263 only took into account tumor cells. Therefore, there was an heterogeneity in this group. Finally, most of papers ( 9 out of 11) we found came from Asian and these results could not represent the whole world population.

To conclude, our work is the first study to systematically estimate the association between PD-L1 expression and survival prognosis in SCLC patients. This meta-analysis indicates that PD-L1 is not an important predictor of most clinicopathological features of SCLC patients. However, our results may predict an improved survival when using $\mathrm{mAb}$ or FDA approved clone specifications in IHC assays.

\section{Acknowledgments}

Funding: This research work was supported by Natural 
Science Foundation Project of Anhui Province (No. 1808085MH267) and Key Research and Development Project of Anhui Province (No. 202004a07020020).

\section{Footnote}

Reporting Checklist: The authors have completed the PRISMA reporting checklist. Available at http://dx.doi. org/10.21037/tcr-20-1512a

Conflicts of Interest: All authors have completed the ICMJE uniform disclosure form (available at http://dx.doi. org/10.21037/tcr-20-1512a). The authors have no conflicts of interest to declare.

Ethical Statement: The authors are accountable for all aspects of the work in ensuring that questions related to the accuracy or integrity of any part of the work are appropriately investigated and resolved.

Open Access Statement: This is an Open Access article distributed in accordance with the Creative Commons Attribution-NonCommercial-NoDerivs 4.0 International License (CC BY-NC-ND 4.0), which permits the noncommercial replication and distribution of the article with the strict proviso that no changes or edits are made and the original work is properly cited (including links to both the formal publication through the relevant DOI and the license). See: https://creativecommons.org/licenses/by-nc-nd/4.0/.

\section{References}

1. Torre LA, Siegel RL, Jemal A. Lung Cancer Statistics. Adv Exp Med Biol 2016;893:1-19.

2. Demedts IK, Vermaelen KY, van Meerbeeck JP. Treatment of extensive-stage small cell lung carcinoma: current status and future prospects. Eur Respir J 2010;35:202-15.

3. Reiss KA, Forde PM, Brahmer JR. Harnessing the power of the immune system via blockade of PD-1 and PD-

L1: a promising new anticancer strategy. Immunotherapy 2014;6:459-75.

4. Horn L, Mansfield AS, Szczesna A, et al. First-Line Atezolizumab plus Chemo-therapy in Extensive-Stage Small-Cell Lung Cancer. N Engl J Med 2018;379:2220-9.

5. Yan F, Pang J, Peng Y, et al. Elevated Cellular PD1/ PD-L1 Expression Confers Acquired Resistance to Cisplatin in Small Cell Lung Cancer Cells. PLoS One 2016;11:e0162925.
6. Ishii H, Azuma K, Kawahara A, et al. Significance of programmed cell death-ligand 1 expression and its association with survival in patients with small cell lung cancer. J Thorac Oncol 2015;10:426-30.

7. Chang YL, Yang CY, Huang YL, et al. High PD-L1 expression is associated with stage IV disease and poorer overall survival in 186 cases of small cell lung cancers. Oncotarget 2017;8:18021-30.

8. Miao L, Lu Y, Xu Y, et al. PD-L1 and c-MET expression and survival in patients with small cell lung cancer. Oncotarget 2017;8:53978-88.

9. Sterne JA, Egger M. Funnel plots for detecting bias in meta-analysis: guidelines on choice of axis. J Clin Epidemiol 2001;54:1046-55.

10. Tsuruoka K, Horinouchi H, Goto Y, et al. PD-L1 expression in neuroendocrine tumors of the lung. Lung Cancer 2017;108:115-20.

11. Yu H, Batenchuk C, Badzio A, et al. PD-L1 Expression by Two Complementary Diagnostic Assays and mRNA In Situ Hybridization in Small Cell Lung Cancer. J Thorac Oncol 2017;12:110-20.

12. Kim HS, Lee JH, Nam SJ, et al. Association of PDL1 Expression with Tumor-Infiltrating Immune Cells and Mutation Burden in High-Grade Neuroendocrine Carcinoma of the Lung. J Thorac Oncol 2018;13:636-48.

13. Liu J, Lu Z, Wang W, et al. Programmed death-ligand 1 positivity can predict improved survival and a lower risk of brain metastasis in patients with resectable small cell lung cancer. Oncol Lett 2018;16:2373-81.

14. Jin J, Si J, Liu Y, et al. Elevated serum soluble programmed cell death ligand 1 concentration as a potential marker for poor prognosis in small cell lung cancer patients with chemotherapy. Respir Res 2018; 19:197.

15. Bonanno L, Pavan A, Dieci MV, et al. The role of immune microenvironment in small-cell lung cancer: Distribution of PD-L1 expression and prognostic role of FOXP3positive tumour infiltrating lymphocytes. Eur J Cancer 2018;101:191-200.

16. $\mathrm{Xu} \mathrm{Y,} \mathrm{Cui} \mathrm{G,} \mathrm{Jiang} \mathrm{Z}$, et al. Survival analysis with regard to PD-L1 and CD155 expression in human small cell lung cancer and a comparison with associated receptors. Oncol Lett 2019;17:2960-8.

17. Qiu YJ, Zhang MZ. PD-L1 expression is related with prognosis of small cell lung cancer. Zhonghua Zhong Liu Za Zhi 2019;41:214-7.

18. Ancevski Hunter K, Socinski MA, Villaruz LC. PDL1 Testing in Guiding Patient Selection for PD-1/PDL1 Inhibitor Therapy in Lung Cancer. Mol Diagn Ther 
2018;22:1-10.

19. Duval S, Tweedie R. Trim and fill: A simple funnel-plotbased method of testing and adjusting for publication bias in meta-analysis. Biometrics 2000;56:455-63.

20. Brahmer JR, Tykodi SS, Chow LQ, et al. Safety and activity of anti-PD-L1 anti-body in patients with advanced cancer. N Engl J Med 2012;366:2455-65.

21. Topalian SL, Hodi FS, Brahmer JR, et al. Safety, activity, and immune correlates of anti-PD-1 antibody in cancer. $\mathrm{N}$ Engl J Med 2012;366:2443-54.

22. Taube JM, Klein A, Brahmer JR, et al. Association of PD1, PD-1 ligands, and other features of the tumor immune microenvironment with response to anti-PD-1 therapy. Clin Cancer Res 2014;20:5064-74.

23. Gadiot J, Hooijkaas AI, Kaiser AD, et al. Overall survival and PD-L1 expression in metastasized malignant melanoma. Cancer 2011;117:2192-201.

24. Takada K, Toyokawa G, Okamoto T, et al. An Immunohistochemical Analysis of PD-L1 Protein Expression in Surgically Resected Small Cell Lung Cancer Using Different Antibodies and Criteria. Anticancer Res 2016;36:3409-12.

25. McLaughlin J, Han G, Schalper KA, et al. Quantitative Assessment of the Heterogeneity of PD-L1 Expression in Non-Small-Cell Lung Cancer. JAMA Oncol 2016;2:46-54.

26. Keir ME, Butte MJ, Freeman GJ, et al. PD-1 and its ligands in tolerance and immunity. Annu Rev Immunol 2008;26:677-704.

27. Chen YB, Mu CY, Huang JA. Clinical significance of programmed death-1 ligand-1 expression in patients with non-small cell lung cancer: a 5-year-follow-up study. Tumori 2012;98:751-5.

28. Ohigashi Y, Sho M, Yamada Y, et al. Clinical significance of Keir programmed death-1 ligand-1 and programmed death-1 ligand-2 expression in human esophageal cancer.
Clin Cancer Res 2005;11:2947-53.

29. Wu C, Zhu Y, Jiang J, et al. Immunohistochemical localization of programmed death-1 ligand-1 (PD-L1) in gastric carcinoma and its clinical significance. Acta Histochem 2006;108:19-24.

30. Gao Q, Wang XY, Qiu SJ, et al. Overexpression of PD$\mathrm{L} 1$ significantly associates with tumor aggressiveness and postoperative recurrence in human hepatocellular carcinoma. Clin Cancer Res 2009;15:971-9.

31. Nomi T, Sho M, Akahori T, et al. Clinical significance and therapeutic potential of the programmed death-1 ligand/ programmed death-1 pathway in human pancreatic cancer. Clin Cancer Res 2007;13:2151-7.

32. Thompson RH, Dong H, Kwon ED. Implications of B7-H1 expression in clear cell carcinoma of the kidney for prognostication and therapy. Clin Cancer Res 2007;13:709s-15s

33. Velcheti V, Schalper KA, Carvajal DE, et al. Programmed death ligand-1 expression in non-small cell lung cancer. Lab Invest 2014; 94:107-16.

34. Droeser RA, Hirt C, Viehl CT, et al. Clinical impact of programmed cell death ligand 1 expression in colorectal cancer. Eur J Cancer 2013;49:2233-42.

35. Schalper KA, Velcheti V, Carvajal D, et al. In situ tumor PD-L1 mRNA expression is associated with increased TILs and better outcome in breast carcinomas. Clin Cancer Res 2014;20:2773-82.

36. Kerr KM, Thunnissen E, Dafni U, et al. A retrospective cohort study of PD-L1 prevalence, molecular associations and clinical outcomes in patients with NSCLC: Results from the European Thoracic Oncology Platform (ETOP) Lungscape Project. Lung Cancer 2019;131:95-103.

37. Akbay EA, Koyama S, Carretero J, et al. Activation of the PD-1 pathway contributes to immune escape in EGFRdriven lung tumors. Cancer Discov 2013;3:1355-63.
Cite this article as: $\mathrm{Hu} \mathrm{Z}, \mathrm{Lu} \mathrm{L}, \mathrm{Fei} \mathrm{Z}, \mathrm{Lv} \mathrm{D}$. Association between clinicopathological features and prognosis significance of PD-L1 expression in small cell lung cancer patients: a systemic review and meta-analysis. Transl Cancer Res 2020;9(9):5508-5516. doi: 10.21037/tcr-20-1512a 